\title{
BMJ Open Healthy food prescription incentive programme for adults with type 2 diabetes who are experiencing food insecurity: protocol for a randomised controlled trial, modelling and implementation studies
}

Dana Lee Olstad (D , , Reed Beall, ${ }^{1}$ Eldon Spackman, ${ }^{1}$ Sharlette Dunn, ${ }^{1}$ Lorraine L Lipscombe, ${ }^{2}$ Kienan Williams, ${ }^{3}$ Richard Oster, ${ }^{4}$ Sara Scott, ${ }^{1}$ Gabrielle L Zimmermann, ${ }^{1,5}$ Kerry A McBrien, ${ }^{1,6}$ Kieran J D Steer, ${ }^{1}$ Catherine B Chan, ${ }^{4,7,8}$ Sheila Tyminski, ${ }^{9}$ Seth Berkowitz (1) , ${ }^{10}$ Alun L Edwards, ${ }^{11}$ Terry Saunders-Smith, ${ }^{1}$ Saania Tariq, ${ }^{1}$ Naomi Popeski, ${ }^{8}$ Laura White, ${ }^{12}$ Tyler Williamson, ${ }^{1}$ Mary L'Abbé, ${ }^{13}$ Kim D Raine, ${ }^{14}$ Sara Nejatinamini, ${ }^{1}$ Aruba Naser, ${ }^{1}$ Carlota Basualdo-Hammond, ${ }^{9}$ Colleen Norris, ${ }^{15,16}$ Petra O'Connell, ${ }^{8}$ Judy Seidel, ${ }^{1,17}$ Richard Lewanczuk, ${ }^{18}$ Jason Cabaj, ${ }^{1}$ David J T Campbell (iD ${ }^{1,11,19}$

To cite: Olstad DL, Beall R, Spackman E, et al. Healthy food prescription incentive programme for adults with type 2 diabetes who are experiencing food insecurity: protocol for a randomised controlled trial, modelling and implementation studies. BMJ Open 2022;12:e050006. doi:10.1136/ bmjopen-2021-050006

- Prepublication history and additional supplemental material for this paper are available online. To view these files, please visit the journal online (http://dx.doi.org/10.1136/ bmjopen-2021-050006)

Received 08 February 2021 Accepted 19 October 2021

Check for updates

(C) Author(s) (or their employer(s)) 2022. Re-use permitted under CC BY-NC. No commercial re-use. See rights and permissions. Published by BMJ.

For numbered affiliations see end of article.

Correspondence to

Dr Dana Lee Olstad;

dana.olstad@ucalgary.ca

\section{ABSTRACT}

Introduction The high cost of many healthy foods poses a challenge to maintaining optimal blood glucose levels for adults with type 2 diabetes mellitus who are experiencing food insecurity, leading to diabetes complications and excess acute care usage and costs. Healthy food prescription programmes may reduce food insecurity and support patients to improve their diet quality, prevent diabetes complications and avoid acute care use. We will use a type 2 hybrid-effectiveness design to examine the reach, effectiveness, adoption, implementation and maintenance (RE-AIM) of a healthy food prescription incentive programme for adults experiencing food insecurity and persistent hyperglycaemia. A randomised controlled trial (RCT) will investigate programme effectiveness via impact on glycosylated haemoglobin (primary outcome), food insecurity, diet quality and other clinical and patient-reported outcomes. A modelling study will estimate longer-term programme effectiveness in reducing diabetes-related complications, resource use and costs. An implementation study will examine all RE-AIM domains to understand determinants of effective implementation and reasons behind programme successes and failures.

Methods and analysis 594 adults who are experiencing food insecurity and persistent hyperglycaemia will be randomised to a healthy food prescription incentive $(n=297)$ or a healthy food prescription comparison group $(n=297)$. Both groups will receive a healthy food prescription. The incentive group will additionally receive a weekly incentive (CDN\$10.50/household member) to purchase healthy foods in supermarkets for 6 months. Outcomes will be assessed at baseline and followup (6 months) in the RCT and analysed using mixed-effects regression. Longer-term outcomes will be modelled using the UK Prospective Diabetes Study outcomes simulation model-2. Implementation processes and outcomes will be continuously measured via quantitative and qualitative data.

\section{Strengths and limitations of this study}

- We will investigate the reach, effectiveness, adoption, implementation and maintenance of a healthy food prescription incentive programme for adults who are experiencing food insecurity and persistent hyperglycaemia.

- A randomised controlled trial and a modelling study will demonstrate the short- and longer-term impacts of the programme on glycosylated haemoglobin, other health-related outcomes, resource use and costs.

- An implementation study will support translation of findings into practice by examining determinants of effective implementation and reasons behind programme successes and failures.

- Patients' medication/insulin regimes may be intensified/de-intensified during the study and thus sensitivity analyses will be conducted to examine the potential impact of such changes on study findings.

Ethics and dissemination Ethical approval was obtained from the University of Calgary and the University of Alberta. Findings will be disseminated through reports, lay summaries, policy briefs, academic publications and conference presentations.

Trial registration number NCT04725630.

Protocol version Version 1.1; February 2022

\section{BACKGROUND}

Type 2 diabetes mellitus (T2DM) imposes a tremendous burden on healthcare systems 
worldwide, as individuals with T2DM incur twice the healthcare costs as their age-matched and sex-matched counterparts. ${ }^{12}$ The total economic costs of diabetes were US $\$ 327$ billion in 2017 in the USA, and CDN\$30 billion in Canada in 2019, making it among the most expensive chronic conditions in both nations. ${ }^{134}$ The human toll on individuals and their families is also substantial in terms of reduced quality of life associated with managing the disease. ${ }^{56}$ Many of these human and economic costs are avoidable, as adherence to a healthy diet within an overall diabetes management plan can yield clinically meaningful improvements in blood glucose levels, which can reduce diabetes complications over time. ${ }^{7-15}$ Average blood glucose levels are most often quantified using the glycosylated haemoglobin level (A1C), which represents the average blood sugar level over the previous 3 months. ${ }^{16}$ An absolute reduction of $0.5 \%$ in A1C is achievable through improving diet quality ${ }^{78}$ and is considered a clinically meaningful difference. ${ }^{17}$

The high and continually escalating costs of many healthy foods ${ }^{18} 19$ represents a formidable barrier to adhering to a healthy dietary pattern for individuals with T2DM, particularly for those who are experiencing food insecurity. ${ }^{20-24}$ Food insecurity refers to inadequate or insecure access to food due to financial constraints ${ }^{25}$ and is a strong predictor of high-cost healthcare use. ${ }^{26}$ Evidence indicates that individuals with T2DM who are experiencing food insecurity have lower diet quality than their food secure counterparts, leading to elevations in blood glucose levels, ${ }^{27-35}$ and high rates of diabetes complications and acute care use. ${ }^{29} 32$ 36-39 Indigenous groups (constitutionally recognised as First Nations, Inuit and Métis) are a population of particular concern, given their disproportionately high rates of both T2DM and food insecurity. ${ }^{40-42}$ The coexistence of food insecurity and T2DM, therefore, has major implications for the sustainability of healthcare systems.

Although it is well known that food insecurity is a primary driver of acute care usage and costs, healthcare providers often lack effective strategies to address it. One approach to better address this problem is to assist patients who are experiencing food insecurity to purchase diabetes-appropriate foods through healthy food prescription programmes, which provide subsidies or incentives to improve access to healthy foods. Preliminary evidence from several studies suggests that these programmes may improve diet quality and self-reported health, while reducing food insecurity, A1C, hypertension and body mass index (BMI), including within Indigenous communities. ${ }^{43-59}$ Moreover, a recent metaanalysis of 13 studies found that healthy food prescription programmes may increase fruit and vegetable intake by 0.8 servings/day, reduce BMI by $0.6 \mathrm{~kg} / \mathrm{m}^{2}$ and reduce A1C by $0.8 \%$, although the certainty of the evidence was rated as very low to moderate. ${ }^{60}$ Qualitative data similarly suggest patients and care providers perceive financial, dietary and health benefits from these programmes, and support their ongoing delivery. ${ }^{43} 5061-63$ Food prescription programmes also appear to be cost-effective, with one recent modelling study indicating that a national healthy food prescription incentive programme in the USA could eliminate US $\$ 100.2$ billion in healthcare costs if implemented over the lifetime of beneficiaries. ${ }^{64}$

Despite some promising initial findings, major knowledge gaps remain pertaining to the impact and optimal implementation of healthy food prescription programmes. ${ }^{60}$ Most prior studies have been small and uncontrolled, and have examined a small number of selfreported outcomes using brief dietary ${ }^{44} 4548365$ and/or food insecurity screeners, ${ }^{47}{ }^{50-53}$ and/or short descriptive surveys, ${ }^{446163}$ rather than objective clinical outcomes. The majority of prior programmes have also subsidised the purchase of fruits and vegetables alone, without considering the relevance of entire dietary patterns to blood glucose levels and health outcomes. ${ }^{7860}$ Moreover, there is virtually no understanding of the effectiveness and costeffectiveness of these programmes over the longer-term, nor of optimal implementation strategies. ${ }^{66}$

We will build on these initial findings through three concurrent studies, including a randomised controlled trial (RCT), a modelling study and an implementation study. We will use a type 2 hybrid effectiveness-implementation design, which entails dual testing of the effectiveness and implementation of an intervention. ${ }^{67}$ Collective findings will be integrated to provide a comprehensive perspective of the reach, effectiveness, adoption, implementation and maintenance (RE-AIM) ${ }^{68} 69$ of a healthy food prescription incentive programme among adults who are experiencing food insecurity and persistent hyperglycaemia. First, the RCT will provide a basis for causal inference pertaining to programme effectiveness. It will entail an incentive to purchase a variety of healthy foods from all food groups, and will be powered to detect clinically meaningful changes in A1C, along with a comprehensive range of objective and selfreported health-related outcomes. A linked modelling study will provide a longer-term perspective of programme effectiveness in reducing diabetes-related complications, along with healthcare use and costs. Finally, a complementary implementation study will encompass quantitative and qualitative measures of all RE-AIM domains to support translation of research findings into practice and policy by helping to understand determinants of effective implementation and reasons behind programme successes and failures.

\section{METHODS}

\section{Overview}

\section{Ethics, privacy and confidentiality}

This research has been approved by the University of Calgary Conjoint Health Research Ethics Board (REB20-0543) and the University of Alberta Health Research Ethics Board Biomedical Panel (Pro00107116). Any protocol deviations will be 
approved in advance by the board and updated in the clinical trials registry. All participants will provide informed consent prior to data collection (online supplemental additional file 1). Participant data will be anonymised and stored on a passwordprotected University server. Only the principal investigators and research coordinators will have access to identifiable participant information and the final trial datasets.

\section{Setting}

This research will take place in Alberta, Canada between May 2021 and December 2023. Participants will primarily be recruited through primary care and diabetes specialty clinics located in urban and rural communities, including clinics with an explicit focus on serving people who identify as Indigenous.

\section{Study oversight}

\section{Scientific steering committee}

A scientific steering committee will oversee all aspects of the research, receive and review reports from the study's advisory boards and subcommittees, and will have final decision-making authority. It will be comprised of the study's five co-principal investigators (DO, ES, RB, LLL and DJTC).

\section{Advisory board}

A multistakeholder advisory board will provide highlevel oversight for the research and will advise the scientific steering committee on study conduct. Members will include policy-makers, academic experts, representatives from Alberta Health Services (the provincial health authority), an Indigenous public health expert and a patient.

\section{Indigenous advisory board}

An Indigenous advisory board will ensure that research activities within Indigenous clinics proceed in a culturally sensitive, relevant, responsive, equitable and reciprocal manner that is guided by Indigenous Ownership, Control, Access and Possession of data principles $(\mathrm{OCAP})^{70}$ and complies with Government of Canada guidance for Indigenous Research. ${ }^{71} 72$ The board will include Indigenous elders and patients, along with academic experts, policy-makers, managers and frontline practitioners from the public health and healthcare sectors who are themselves Indigenous, or who work closely with Indigenous peoples.

\section{Primary care clinic subcommittee}

The primary care clinic (PCC) subcommittee will include PCC managers, staff and patients. As participant recruitment and implementation of the intervention unfolds, PCC managers and staff will collect feedback from their respective clinics and will share it with the larger group as a learning tool and to inform ongoing adaptations.

\section{Implementation support team}

The implementation support team will consist of research coordinators and assistants who will execute the daily tasks required to administer, plan, support, monitor and evaluate the healthy food prescription incentive programme.

\section{Patient and public involvement}

This research has been informed by substantial prior ${ }^{73-77}$ and ongoing engagement with patients experiencing financial barriers to chronic disease care. Patient partners (who are not study participants) will help to pilot test infrastructural supports (eg, healthy food prescription pamphlet, usability of the list of eligible foods), care pathways and implementation processes, and will be members of the advisory boards and PCC subcommittee. Patients who are study participants will provide continuous programme feedback via a dedicated study helpline/email, and by completing implementation fidelity checklists. At the conclusion of the study, participants will be invited to describe their programme experiences via a postintervention questionnaire and during in-depth, semistructured interviews.

Lands and food hold deep cultural, symbolic and spiritual significance for Indigenous peoples. ${ }^{78}$ Staff and patients from Indigenous PCCs will codesign clinical care pathways and other procedures that are context-specific and culturally appropriate for Indigenous patients, and that respect and promote Indigenous worldviews, particularly those surrounding food procurement and consumption. We will ensure that representatives from Indigenous clinics are involved at all stages of the research, including study design, pilot testing infrastructural supports, interpreting results and formulating conclusions, and that their agreement is obtained prior to communicating any research findings that pertain to them. As previously described, the Indigenous advisory board will also oversee all aspects of the research.

\section{Evaluation framework and theory of change}

RE-AIM $^{6869}$ will provide a structured means of integrating data from the RCT, modelling and implementation studies to understand the RE-AIM of the healthy food prescription incentive programme.

Our theory of change (figure 1) draws on Barnard et $a l \mathrm{~s}^{79}$ conceptual model linking material needs insecurities with diabetes outcomes, and posits that reduced food insecurity and improved diet quality will be key mediators of improved blood glucose levels (quantified via A1C), which will help to reduce diabetes complications, and healthcare resource use and costs. Each construct will be examined to affirm or disprove the proposed pathway.

\section{Randomised controlled trial}

The RCT protocol adheres to the Standard Protocol Items: Recommendations for Interventional Trials (SPIRIT) and Template for Intervention Description and Replication (TIDieR) reporting guidelines (table 1; online supplemental additional file 2-4). 


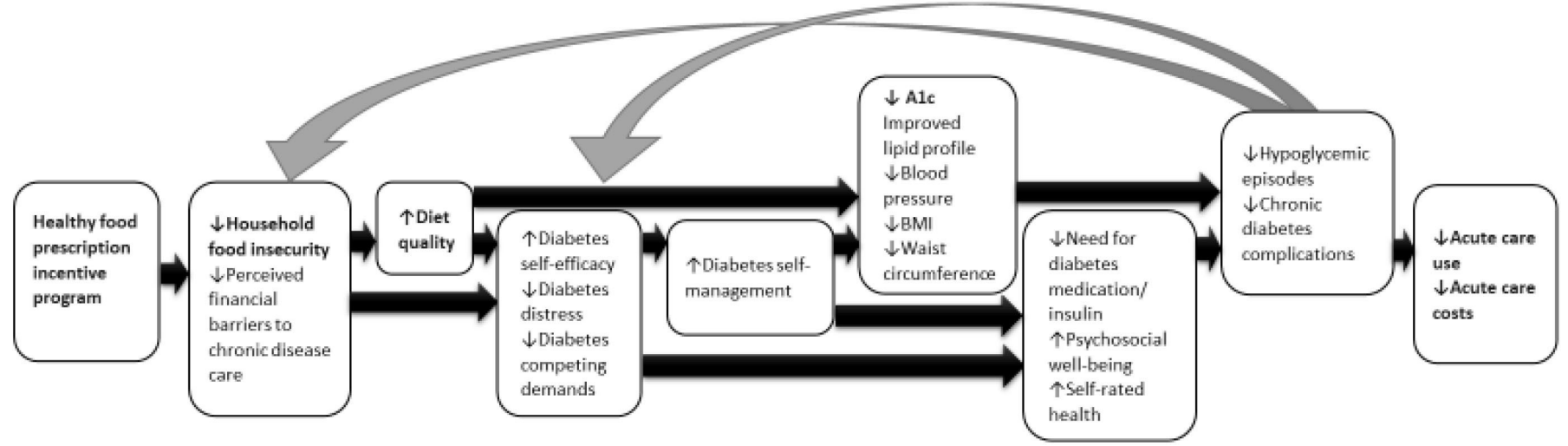

Figure 1 Healthy food prescription programme logic model. A1C an indicator of average blood glucose levels over the previous 3 months. A1C, glycosylated haemoglobin.

\section{Study design and objectives}

A 6-month, parallel-group RCT will examine the effectiveness of a healthy food prescription incentive programme, compared with a healthy food prescription alone, in improving the following outcomes among 594 adults who are experiencing food insecurity and persistent hyperglycaemia (ie, A1C 7\%-12\%):

1. Primary outcome: Average blood glucose levels measured by A1C.

2. Secondary outcomes:

a. Blood glucose levels: Proportion of patients with elevated A1C (ie, $\geq 8.5 \%$ ); blood glucose measured by fructosamine.

b. Dietary intake: Diet quality; skin carotenoids.

c. Intermediate clinical outcomes: Blood lipids; blood pressure; BMI; waist circumference; need for antihyperglycaemic medication/insulin.

d. Patient-reported outcomes: Psychosocial well-being; self-rated health; diabetes self-efficacy; diabetes selfmanagement; diabetes distress; diabetes competing demands; perceived financial barriers to chronic disease care; hypoglycaemic episodes; household food insecurity.

3. Exploratory outcomes: Subjective social status; perceived income adequacy; work productivity and activity impairment; medication and physical activity adherence.

\section{Primary care clinics}

PCCs will be recruited, including urban, rural and Indigenous clinics. To be eligible, clinics must serve lower-income patients, agree to allow their physicians, registered dietitians and/or nurses to dispense healthy food prescriptions, appoint a staff member to liaise with the implementation support team, and be willing to receive training. The final list of study sites, currently projected at 30 clinics, will be available in the clinicaltrials.gov registry.

\section{Participants}

Healthcare providers will use information from electronic medical records to identify patients with T2DM and persistent hyperglycaemia (ie, A1C 7\%-12\%), including patients living in rural and urban areas, and those who identify as Indigenous. Potentially eligible patients will be invited to complete a brief screening questionnaire to identify risk of food insecurity based on the Hunger Vital Sign, ${ }^{80-82}$ and perceived income adequacy. ${ }^{83-85}$ Eligible patients will be adults (18-85 years) with T2DM (or diabetes of unknown aetiology) and persistent hyperglycaemia (ie, A1C 7\%-12\%) who are experiencing food insecurity and/or perceive that it is difficult/very difficult to make ends meet, do not reside in a facility that provides meals (eg, shelter, long-term care, prison), and can communicate in English or have someone to translate. Patients will be excluded if they have an $\mathrm{A} 1 \mathrm{C}<7 \%$ or $>12 \%$ (given the recommendation for antihyperglycaemic treatment escalation for those with $\mathrm{A} 1 \mathrm{C}>12 \%$ ), have signs/symptoms of metabolic decompensation, have an eating disorder, have experienced diabetic ketoacidosis or a hyperglycaemic hyperosmolar emergency in the past year, or if they experienced a severe hypoglycaemic event in the past 3 months. Patients will also be excluded if they are pregnant or trying to conceive, breast feeding, participating in other clinical trials, if someone in their household is currently or has previously participated, if they are unwilling/unable to shop in study-affiliated supermarkets for the next 6 months, if they plan to leave Canada for more than 2 weeks in the next 6 months, or if they will not be able to complete data collection at 6 months.

Eligible patients will be asked to provide consent to their healthcare provider to be contacted by the research team. A research assistant will contact patients to confirm all eligibility criteria have been met, obtain informed consent and provide instructions for collection of baseline data. Participants may elect to report baseline patient-reported data immediately over the telephone, or independently via the study's online data collection platforms. Any patients identified as at risk of food insecurity at screening, but who do not respond affirmatively to any of the items on the full 18-item Household Food Security Survey Module or who do not indicate that it is difficult/very difficult to make ends meet during baseline 


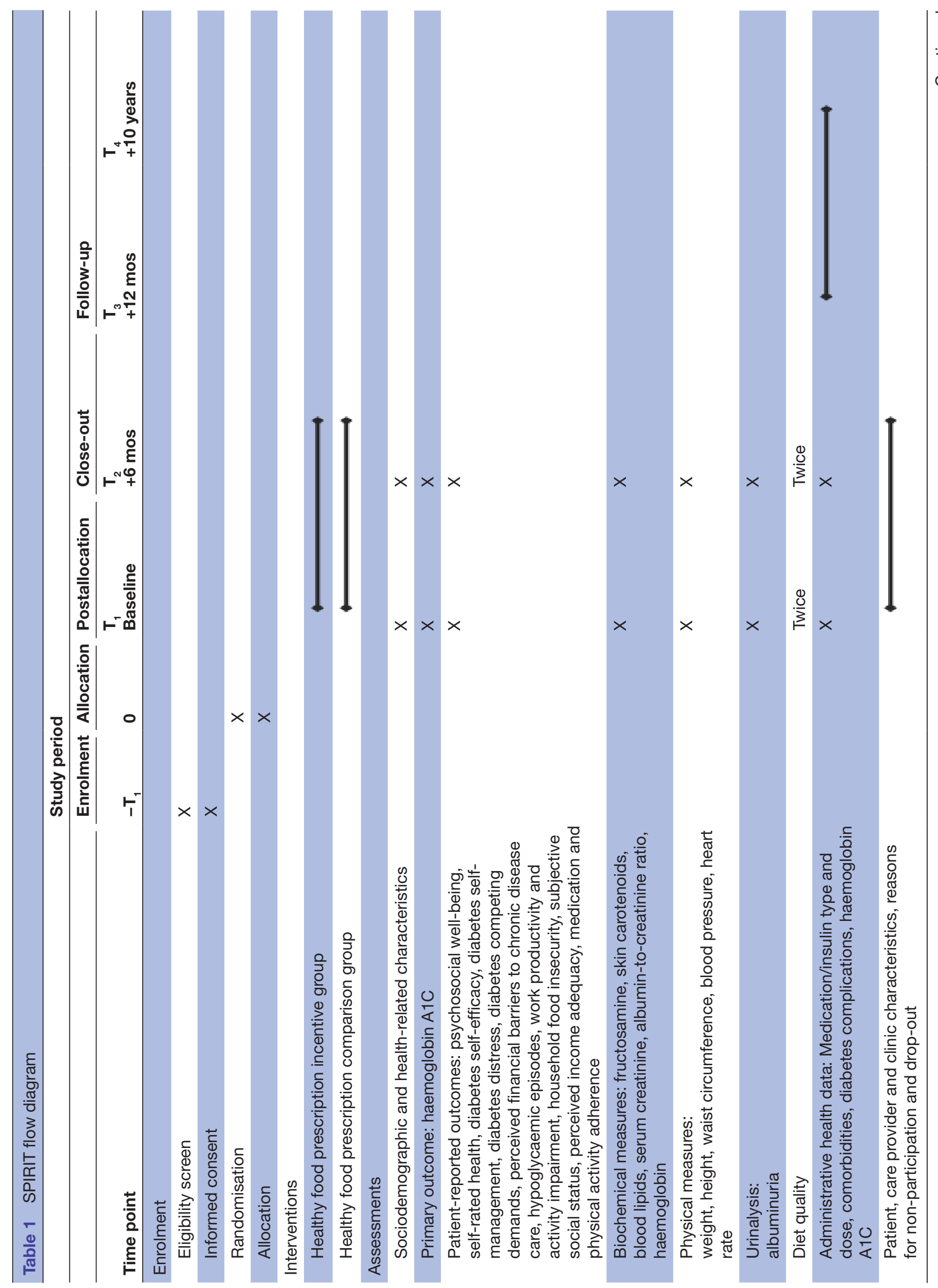

음

음

$\stackrel{\circ}{c}$

$\stackrel{\mathbb{\Phi}}{\square}$ 


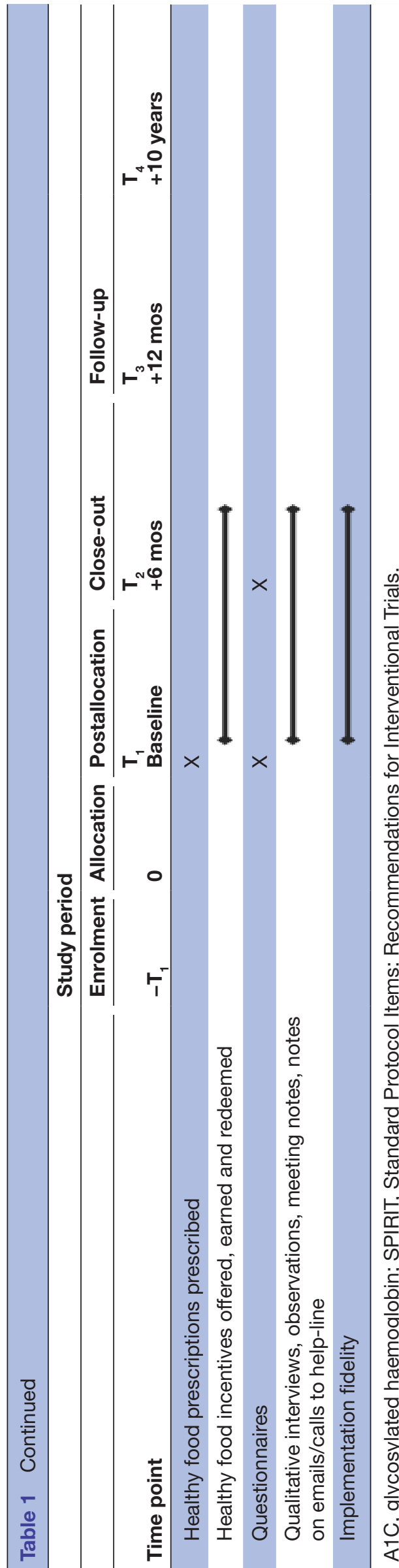

data collection will be excluded. Participants will have biochemical and physical measurements performed at a community laboratory or at their PCC. Participants with an A1C outside the $7 \%-12 \%$ range will be excluded at that point. All participants will subsequently receive a healthy food prescription pamphlet from a healthcare provider (ie, physician, nurse, registered dietitian) and a brief, high-level overview of its contents using standardised teaching guidelines, either virtually or in-person during a clinic visit.

\section{Sample size calculation}

Based on local administrative data, we expect a mean baseline $\mathrm{A} 1 \mathrm{C}$ of $8.5 \%(\mathrm{SD}=1.4 \%)$ in our population. ${ }^{86}$ Assuming $5 \%$ type I error, $30 \%$ attrition ${ }^{87}$ and potential design effects based on sampling in different clinics $(25 \%$ inflation), 594 participants are required for $90 \%$ power to detect a difference in $\mathrm{AlC}$ of $0.5 \%$, which is often considered a minimally important clinical difference. ${ }^{17}$

\section{Randomisation and blinding}

Following baseline data collection and delivery of the healthy food prescription pamphlet, participants will be randomised to a healthy food prescription incentive $(\mathrm{n}=297)$ or a healthy food prescription comparison group $(\mathrm{n}=297)$ with a 1:1 allocation ratio using a computergenerated, concealed, blocked randomisation sequence created by an independent statistician. Blocking variables will include gender, clinic type/location (urban, rural, Indigenous) and baseline A1C (7\%-8.5\%, 8.6\%$12 \%)$. Allocation concealment will be ensured via secure storage of the randomisation sequence separately from the participant database, which will only be accessible by the statistician. To ensure researcher blinding, allocation assignment will be operationalised via REDCap (Research Electronic Data Capture) following completion of baseline data collection. Intervention assignment will be communicated by research assistants via a telephone call. Participants cannot be blinded to treatment allocation, however details of the healthy food incentive, including its monetary value and the types of foods that are eligible, will not be divulged to participants in the comparison group. Care providers, individuals who collect biochemical and physical measurements and data analysts will be blinded to group allocation.

\section{INTERVENTION}

Development of the healthy food prescription incentive programme was informed by the social prescribing literature, Research to Equip Primary Healthcare for Equity principles of equity-oriented healthcare, ${ }^{88}$ initiatives elsewhere (eg, Wholesome Wave ${ }^{89}$ ), and stakeholder consultation. The comparison group will receive a onetime healthy food prescription pamphlet. The incentive group will receive a one-time healthy food prescription pamphlet and a weekly incentive valued at CDN\$10.50/ household member (ie, CDN\$1.50/household member 
per day) to purchase healthy foods in study-affiliated supermarkets. Thus, the study is designed to test the impact of a healthy food incentive, which is an intervention that targets economic rather than knowledgerelated barriers to healthy eating. Aside from labelling the nutritional advice delivered as a 'prescription' (which may have some independent impact on participants' behaviour), the healthy food prescription closely mimics current care (ie, nutrition counselling) and is unlikely to substantially change dietary intake in the context of significant economic constraints. ${ }^{90-95}$ The value of the incentive exceeds the benefit provided by many similar US programmes ${ }^{568}$ in order to more closely bridge the gap in food spending between food secure and insecure households in Canada. ${ }^{96}$ The value of the incentive that each household will receive will be calculated based on the number of household members at baseline and will remain consistent throughout the intervention regardless of changes in household size. A household member is defined as a partner or a dependent child or adult who resides at the same location at least $50 \%$ of the time. The intervention will be delivered over 6 months to allow sufficient time for dietary changes to be reflected in approximately two A1C cycles. ${ }^{97}$

The healthy food prescription pamphlet was designed by registered dietitians and modelled after a previous food prescription programme to be a visually appealing, low literacy resource ${ }^{98}$ (online supplemental additional file 5). The cover page contains the following preprinted prescription 'I prescribe a healthy eating pattern of minimally processed foods that have little to no added fat, sugar or salt,' with space for the care provider to add their signature, date and patient information. The inner pages outline an evidence-based healthy dietary pattern, with key messages to consume a variety of whole, minimally processed foods from all food groups with little to no added fat, sugar or salt, to spread carbohydrate foods over the day, to satisfy thirst with water, and to avoid sugary drinks, refined grains, sweets, confectionary and desserts. ${ }^{799}$ A diabetes-appropriate recipe is provided along with links to connect patients with sources of free/ lower-cost food, additional recipes, nutrition information, other helpful community services and sources of emergency food assistance. Feedback from PCC staff, patients and the advisory boards was incorporated into the final version of the pamphlet.

The healthy food incentive consists of a weekly incentive valued at $\mathrm{CDN} \$ 10.50 /$ household member to purchase healthy foods in study-affiliated supermarkets. The list of incentive-eligible foods includes whole, minimally processed foods with little to no added fat, sugar or salt from all food groups ${ }^{799}$ (table 2). Once a household reaches their spending threshold they will receive an immediate payback in loyalty card points of the same value (ie, a redeemable value of CDN\$10.50/household member). For instance, if a two-person household spends CDN\$21 over a 1-week period on incentive-eligible foods (in a single shop or across multiple shops), they will
Table 2 Foods that qualify for the healthy food incentive

\begin{tabular}{ll}
\hline Food group & Eligible items \\
\hline Vegetables and fruits & Fresh vegetables and fruit \\
& Frozen vegetables and fruit \\
& Canned vegetables \\
\hline Meat, poultry and fish & Fresh meat, poultry and fish \\
& Canned fish \\
\hline Meat alternatives & Dried or canned lentils, chickpeas \\
& or beans \\
& Whole eggs \\
& Whole almonds \\
& White cow's milk \\
\hline Dairy products & Unsweetened fortified soy \\
beverage \\
Plain yoghurt \\
Hard cheddar cheese \\
Whole grain pasta \\
\hline Whole grain foods
\end{tabular}

receive a loyalty card points payback with a redeemable value of CDN\$21. The value of the points incentive is capped at CDN $\$ 10.50 /$ household member, meaning that households that exceed this spending threshold will not receive additional points, while those that do not meet this threshold will not receive any points that week. The offers will be renewed weekly. While progress towards the minimum spend for triggering the points payback will be reset weekly, loyalty card points never expire and will carry over between weeks if left unspent. Loyalty card points can be redeemed in $\mathrm{CDN} \$ 10$ increments to purchase anything in store, with no restrictions. Importantly, while there is no requirement to do so, participants may use loyalty card points as payment for purchases that will earn them even more points in return (ie, by using their points to purchase incentive-eligible foods).

At baseline, participants' loyalty cards will be preloaded with the dollar amount of points that matches their household size so that they can earn their first points payback by purchasing incentive-eligible foods without paying outof-pocket. Participants will then be encouraged to repeat this pattern of redeeming loyalty card points weekly to earn more loyalty card points for shopping the following week. Participants who run out of loyalty card points to meet their offer's spending threshold can request a second allocation of loyalty card points for resuming the cycle of redeeming points to earn more points without spending out-of-pocket.

A booklet was created with pictures of incentive-eligible foods to assist participants to locate them. The process of collecting and redeeming loyalty card points using the 
booklet was pilot tested with two participants, with good results. Research assistants will review the booklet and rules pertaining to how loyalty card points may be earned and redeemed with participants prior to the intervention. They will also assist participants to download the supermarket's app where they can review details of the healthy food incentive, monitor their loyalty card points balance, and their progress towards meeting their weekly spending threshold. Participants without mobile phones can also login to their loyalty card account via computer or consult the bottom of their store receipt to view the number of loyalty card points they have accumulated. Research assistants will email/text participants at the beginning of the intervention to identify and resolve any difficulties they may have had in collecting and/or redeeming loyalty card points. Participants will also have continuous access to a study email and telephone help-line where they can ask study-related questions and inquire about their loyalty card points balance or spending progress.

\section{DATA COLLECTION}

To support retention, all participants (regardless of treatment allocation) will receive CDN\$100 following completion of data collection at baseline ( 0 months) and again at follow-up (6 months).

\section{Questionnaires}

Electronic questionnaires will encompass sociodemographic and health-related items, dietary intake in the previous 24 hours, and a variety of patient-reported outcomes. The final questionnaires will be reviewed by the advisory boards and scientific steering committee to establish face and content validity, and will be pretested with patients.

Sociodemographic and health-related variables will be recorded in REDCap using existing items from the Canadian Community Health Survey where available, ${ }^{100}$ including date of birth, sex at birth, gender identity, race/ethnicity, years lived in Canada, household size and composition, number of household members with T2DM, educational attainment, employment status, marital status, annual household income, main income source, access to extended health benefits, participation in income support programmes, smoking status, housing status, medication/insulin type and dose, duration of diabetes and physical activity level. ${ }^{101}$

Patient-reported outcomes will be assessed using the following validated scales: WHO Well-Being Scale, ${ }^{102}$ Stanford Diabetes Self-Efficacy Scale, ${ }^{103}{ }^{104}$ Diabetes SelfManagement Questionnaire, ${ }^{105}{ }^{106}$ Problem Areas in Diabetes Scale-5 to assess diabetes distress, ${ }^{107}$ EQ-5D-5L to assess self-rated health, ${ }^{108}$ hypoglycaemic episodes, ${ }^{30}$ Work Productivity and Activity Impairment Questionnaire, ${ }^{109}$ Health Canada's Household Food Security Survey Module to assess experiences of marginal, moderate and severe household food insecurity in the past 6 months ${ }^{110-112}$ and medication adherence. ${ }^{113} \mathrm{We}$ will also assess diabetes competing demands ${ }^{114}$ and perceived financial barriers to chronic disease care, the latter of which has undergone testing via focus groups and cognitive interviews. ${ }^{115}$ Subjective social status will be assessed using the MacArthur Scale of Subjective Social Status national and community ladders. ${ }^{116}{ }^{117}$ Participants will report perceived income adequacy by answering the question: 'Thinking about your total monthly income, how difficult or easy is it for you to make ends meet?' ${ }^{83-85}$

Quality of dietary intake will be assessed using the online Automated Self-Administered 24-hour Dietary Recall for Canada (ASA24-Canada-2018) whereby all participants will report all foods and beverages consumed from midnight to midnight the previous day, including location of consumption and dietary supplements. ${ }^{118-120}$ The ASA24 has demonstrated good correspondence with standardised interviewer administered dietary recalls and with true intakes. ${ }^{119} 121$ Participants will receive an unannounced email/text 2-4 days later prompting them to complete a second dietary recall to provide a more precise estimate of usual intake. ${ }^{122}$ Dietary intake data will be used to calculate subscores and an overall Healthy Eating Index-2015 score from 0 to 100 for each participant, which provides a valid assessment of overall diet quality consistent with recommendations in the healthy food prescription pamphlet. ${ }^{123} 124$

To reduce missing data, REDCap will be configured to require a response prior to proceeding to the next question, although 'don't know' and 'refuse to answer' will be response options. Research assistants will also review all completed questionnaires and will telephone participants within 24 hours to request responses to any unanswered questions.

\section{Clinical measurements}

Biochemical measurements will include quantification of blood glucose levels via A1C (standardised to the Diabetes Complications and Control Trial) ${ }^{125-128}$ and fructosamine, as A1C can be unreliable for some patients and fructosamine is more sensitive to acute changes. ${ }^{129}$ Blood lipids (total, HDL and LDL cholesterol, triglycerides, apolipoprotein B), serum creatinine (to calculate estimated glomerular filtration rate), albumin-to-creatinine ratio and haemoglobin concentration will also be quantified. Participants will provide a urine sample to detect albuminuria. All samples will be analysed by Alberta Precision Laboratories and DynaLIFE Medical Labs.

Physical measurements will adhere to standardised measurement protocols and will be performed a minimum of two times by trained researchers/clinicians, including weight and height to calculate BMI, waist circumference, systolic and diastolic blood pressure (using oscillometric devices approved by Hypertension Canada) and heart rate. Skin carotenoids will be assessed using Pharmanex Biophotonic Scanners as biomarkers of fruit and vegetable intake. ${ }^{130}$ 
Administrative health data

A1C levels and information on comorbidities and diabetes complications will be obtained from Alberta Health Services' Analytics, Data Integration, Measurement and Reporting database. The secondary outcome of need for antihyperglycaemic medication/insulin will be quantified by monitoring changes in medication/ insulin use (ie, initiation or discontinuation), type (ie, Metformin, Sulfonylureas, Repaglinide, DPP-4 inhibitors, GLP1 receptor agonists, SGLT2-inhibitors, Acarbose, Thiazolidinediones, Statins or other lipid-lowering agents, Renin-angiotensin aldosterone antagonists and other anti-hypertensive agents) and dosage recorded in the Pharmaceutical Information Network Database. ${ }^{131}$ We will also collect administrative data on health events and healthcare use on an ongoing basis postintervention to support understanding of longer-term outcomes.

\section{Implementation fidelity}

Implementation fidelity will be continuously assessed using a combination of quantitative and qualitative measures as part of the implementation study (described below).

\section{Data monitoring and adverse events}

We have not established stopping guidelines or a data monitoring committee as the intervention is low risk. In addition, physicians will be free to adjust patients' medication regimens to achieve improved glycaemia as per usual care. Given that serious adverse events are unlikely, adverse events will not be monitored and no provisions have been made for compensation. Interim analyses will not be conducted. At the conclusion of the study, participants will continue to be followed by their care providers.

\section{Data analysis}

Mixed-effects linear and multinomial logistic/ordinal regression will assess group differences in outcomes at follow-up, adjusted for baseline values of each outcome, blocking variables and covariates (specific to each outcome), with subgroup analyses by gender, severity of food insecurity, rural residence, Indigenous status, baseline A1C $(7 \%-8.5 \%, 8.6 \%-12 \%)$ and insulin use. Participant-specific and PCC-specific variations will be modelled using random effects. A dose-response analysis will examine whether outcomes depend on the value of healthy food incentives earned and/or redeemed. Missing data will be handled using full information maximum likelihood under a missing at random assumption. Analyses will be intention-to-treat using all available data.

For the primary outcome of A1C, covariates will include the following: age, gender, race/ethnicity, educational attainment, years lived in Canada, number of children living in the home, marital status, change in number of household members since baseline, access to extended health benefits, participation in other income support programmes, diabetes duration and physical activity level.
Sensitivity analyses

Sensitivity analyses will examine outcomes among patients whose antihyperglycaemic medication/insulin regimen was unchanged during the 3 months prior to the study, throughout the study period, and when patients taking insulin are excluded. We will also examine the impact of excluding patients who were started on lipid-lowering or anti-hypertensive therapy from models assessing impact on blood lipids and blood pressure, respectively. Additional sensitivity analyses will consider the impact on findings when food insecurity is modelled as a continuous, rather than as a categorical outcome, ${ }^{132}$ when diet quality is assessed via the new Healthy Eating Food Index-2019, ${ }^{133}$ and when an indicator of energy intake misreporting (ie, the ratio of reported energy intake to estimated energy expenditure) is included in models assessing impact on diet quality.

We will also consider the impact on findings when models are adjusted for changes in medication/insulin type and dosage that occurred between baseline and follow-up. We propose to use a novel scoring system that attempts to match the changes made with the expected clinical impact on A1C. ${ }^{134}$ The following changes will be assigned one point (expected change in A1C of $~ 0.5 \%$ ): less than full dose of Metformin $(<2000 \mathrm{mg} /$ day $)$, Sulfonylureas (Gliclazide $<60 \mathrm{mg}$ /day, Glyburide $<10 \mathrm{mg}$ /day) or Repaglinide ( $<5 \mathrm{mg}$ /day); any dose of DPP-4 inhibitor, SGLT2-inhibitor or Acarbose; initiation of basal insulin or insulin adjustment by $<20 \%$ of total daily dose. Two points (expected change in A1C of $\sim 1 \%$ ) will be assigned for: full dose of Metformin, Sulfonylureas or Repaglinide; any dose of GLP1 receptor agonists or Thiazolidinedione; initiation of bolus insulin or insulin adjustment of $>20 \%$ of total daily dose. Points will be attributed cumulatively for all medication/insulin changes. Addition of medication/insulin will be scored positively and reductions scored negatively to arrive at a final cumulative medication/insulin adjustment score for each participant.

Markov chain Monte Carlo multiple imputation, inverse probability weighting and available case analysis will be used to investigate the impact of different assumptions about missing data on estimated programme impacts. ${ }^{135-137}$ Pattern mixture methods models ${ }^{138}$ will be used to explore the robustness of study findings to the assumption that data were missing not at random. ${ }^{139}$

\section{Modelling study}

Study design and objectives

A modelling study will estimate longer-term effectiveness of the healthy food prescription incentive programme on diabetes-related complications, resource use and costs.

\section{Data collection}

The individual-level data required as inputs for the model will be captured in the baseline and follow-up assessment phase of the RCT, as previously described. Model inputs required to estimate programme impact on longer-term resource use and costs will be obtained 
from Alberta Health Services' Analytics, Data Integration, Measurement and Reporting database, including emergency department, inpatient, specialist, general practice and urgent care costs. The costs of the intervention will include administrative costs associated with implementing the programme and the costs of incentives at a household level. The time to administer the programme will be based on the non-research hours of the study personnel and unit costs will be obtained from the Alberta Wage and Salary Survey. ${ }^{140}$

\section{Data analysis}

The potential longer-term health and economic impacts of the healthy food prescription incentive programme will be modelled using the validated UK Prospective Diabetes Study outcomes simulation model-2. ${ }^{141}$ Healthrelated model outputs will include differences between the incentive and comparison groups in cardiovascular events, amputation, blindness, renal failure, diabetic foot ulcers, and mortality over 1 year, 5 years and lifetime scenarios. Model outputs related to the economic impacts of the intervention will include the incremental difference in costs and quality-adjusted life-years ${ }^{142}$ between the incentive and comparison groups, the incremental cost-effectiveness ratio and the net benefit. A budget impact analysis will explore the difference in costs (eg, prescriptions, physician visits, hospitalisations) considering the RE-AIM domains, and return on investment from the public payer perspective over 1 year, 5 years and lifetime scenarios.

\section{Implementation study}

Study design and objectives

A mixed-methods implementation study will evaluate the RE-AIM ${ }^{6869}$ of the healthy food prescription incentive programme in order to understand determinants of effective implementation and reasons behind programme successes and failures (table 3). The Consolidated Framework for Implementation Research (CFIR) consolidates determinants of effective implementation into five domains (intervention characteristics, inner setting, outer setting, characteristics of individuals, implementation process), and will accordingly structure our investigation of determinants of effective implementation, including barriers and facilitators, within RE-AIM's implementation domain. ${ }^{143}$

\section{Implementation process}

The implementation process will unfold according to the four phases and action-oriented steps in the Quality Implementation Framework (QIF). ${ }^{144145}$

QIF phase 1: Initial considerations regarding the host setting

1. Stakeholder buy-in: Partnership agreements will be finalised with all stakeholders.

2. Implementation support team: An implementation support team will be formed to administer, plan, support, monitor and evaluate implementation of the intervention.

3. Training: Study personnel will be trained in principles of equity-oriented care 88146147 and study procedures.

Table 3 Logic model for the implementation of a healthy food prescription incentive programme

Goal: to support adults who are experiencing food insecurity and persistent hyperglycaemia to manage their diabetes with a healthy diet.

Situation: In Alberta, more than 54000 adults are experiencing food insecurity and type 2 diabetes, including 13600 Indigenous individuals who bear a disproportionately high burden ${ }^{171-174}$ This group of Albertans incurs CDN $\$ 842$ million/year in healthcare costs, with a small subset of 9600 individuals with persistent hyperglycaemia incurring nearly one-quarter of these costs. ${ }^{20} 24170171175$ Nevertheless, although it is well known that food insecurity is a primary driver of acute care usage and costs, primary care providers often lack effective strategies to address it.

\begin{tabular}{|c|c|c|c|c|c|}
\hline Inputs & Activities & Outputs & Short-term outcomes & $\begin{array}{l}\text { Longer-term } \\
\text { outcomes }\end{array}$ & Impact \\
\hline $\begin{array}{l}\text { Patient-oriented research, } \\
\text { with patients as partners } \\
\text { A type } 2 \text { hybrid } \\
\text { effectiveness- } \\
\text { implementation study } \\
\text { design } \\
\text { Scientific committee, } \\
\text { advisory boards and PCC } \\
\text { subcommittee } \\
\text { PCC support and } \\
\text { infrastructure } \\
\text { Organisational champions } \\
\text { Funding and in-kind } \\
\text { support from Alberta } \\
\text { Innovates, Alberta Blue } \\
\text { Cross, Alberta Health } \\
\text { Services and Nu-Skin } \\
\text { Implementation support } \\
\text { team } \\
\text { Technical support }\end{array}$ & $\begin{array}{l}\text { Development } \\
\text { of partnership } \\
\text { agreements } \\
\text { Readiness, capacity, } \\
\text { barriers/facilitators } \\
\text { and implementation } \\
\text { assessments } \\
\text { Cocustomisation } \\
\text { of care pathways } \\
\text { and implementation } \\
\text { strategies } \\
\text { Education and } \\
\text { training, including } \\
\text { booster training } \\
\text { Ongoing monitoring } \\
\text { and evaluation } \\
\text { Regular } \\
\text { communication, } \\
\text { including continuous } \\
\text { implementation } \\
\text { feedback }\end{array}$ & $\begin{array}{l}\text { Healthy food } \\
\text { prescriptions } \\
\text { prescribed } \\
\text { Healthy food } \\
\text { incentives offered, } \\
\text { earned and redeemed } \\
\text { Patient, care provider } \\
\text { and PCC participation } \\
\text { Staff training } \\
\text { Patient and provider } \\
\text { experiences and } \\
\text { perceived outcomes } \\
\text { Determinants } \\
\text { of effective } \\
\text { implementation } \\
\text { Reasons for } \\
\text { programme } \\
\text { successes/failures } \\
\text { Cost-effectiveness } \\
\text { analysis }\end{array}$ & $\begin{array}{l}\text { Successful integration } \\
\text { of care pathways } \\
\text { within PCC workflows } \\
\text { Increased awareness } \\
\text { of effective strategies } \\
\text { to reduce food } \\
\text { insecurity } \\
\text { Increased } \\
\text { empowerment for } \\
\text { patients and care } \\
\text { providers } \\
\text { Increased care } \\
\text { provider motivation to } \\
\text { sustain care pathways } \\
\text { Improved diet quality } \\
\text { Reduced food } \\
\text { insecurity } \\
\text { Improved diabetes } \\
\text { management }\end{array}$ & $\begin{array}{l}\text { Improved quality } \\
\text { of care } \\
\text { Improved patient } \\
\text { satisfaction } \\
\text { Improved } \\
\text { glycaemia } \\
\text { Reduced } \\
\text { chronic diabetes } \\
\text { complications } \\
\text { Commitments } \\
\text { from Alberta } \\
\text { Health Services, } \\
\text { PCCs, Alberta } \\
\text { Blue Cross and } \\
\text { supermarkets } \\
\text { to collaborate } \\
\text { for longer-term } \\
\text { sustainability }\end{array}$ & $\begin{array}{l}\text { Decreased } \\
\text { acute care } \\
\text { usage } \\
\text { Decreased } \\
\text { acute care } \\
\text { costs }\end{array}$ \\
\hline
\end{tabular}

PCC, primary care clinic. 
4. Assess needs, fit, capacity, readiness and adaptations: Implementation strategies will be tailored by clinic using a theory-informed modified conjoint analysis ${ }^{148}$ in which PCC staff will complete a questionnaire to identify potential implementation barriers and facilitators within the five domains of CFIR. Researchers will use the CFIR-Expert Recommendations for Implementing Change compilation matching tool to identify strategies to mitigate the barriers and leverage the facilitators identified by each clinic. ${ }^{143} 148-152$

5. Preimplementation planning and adaptations: The implementation support team will develop a preimplementation plan and timeline and will execute it, including codeveloping infrastructural supports, training modules and care pathways with PCG staff and patients. The Indigenous advisory board will progress relationship building with Indigenous PCCs and will work with them to adapt infrastructural supports and care pathways as required.

6. Capacity building and supportive organisational climate: PCC staff will be trained in principles of equityoriented care $e^{88} 146147$ and study procedures. Training sessions and codesign processes will enhance buy-in and readiness to change. One staff designate per organisation will liaise with the implementation support team weekly and will serve as an organisational champion.
7. Study planning: The implementation support team will develop study protocols and procure materials for all three studies.

QIF phase 2: Creating a structure for implementation

1. Implementation planning and adaptations: The implementation support team will use findings from the modified conjoint analysis to develop a detailed implementation plan and timeline, cocustomise it with PCCs, and assign specific roles and responsibilities. Incentive-related procedures will be finalised with our supermarket partner.

QIF phase 3: Implementation and ongoing implementation structure

1. Programme implementation and data collection: The healthy food prescription incentive programme will be implemented and data collection for the RCT and modelling study will proceed (figure 2).

2. Technical support and communication: The implementation support team will provide ongoing support to PCC staff, including via weekly meetings with staff designates. Booster training sessions will be held when new/ modified processes are introduced and for new staff.

3. Implementation study and feedback mechanisms: The implementation support team will collect data continuously for the implementation study. Ongoing monitoring and provision of feedback to PCCs will support continuous quality improvement.

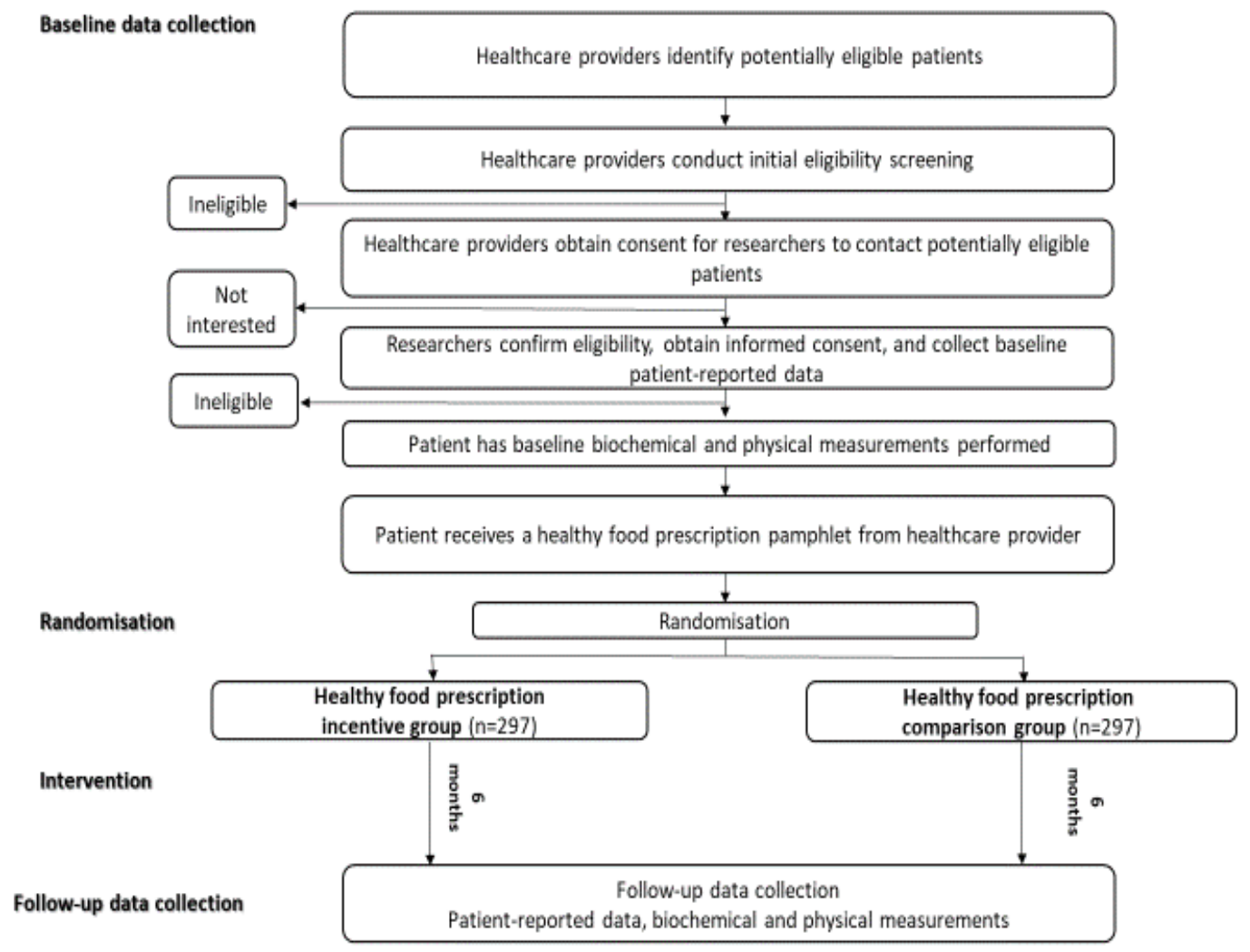

Figure 2 Healthy food prescription programme care pathway. 
QIF phase 4: Improving future applications

1. Data analysis: The research team will analyse and integrate data from all three studies.

2. Knowledge translation and learning from experience: The research team and advisory boards will jointly interpret and disseminate findings. Outcomes from a deliberative dialogue ${ }^{153154}$ knowledge translation event will inform sustainability planning.

\section{Data collection}

Implementation processes and outcomes related to all five RE-AIM domains, and determinants of effective implementation within CFIR domains, will be repeatedly measured via quantitative and qualitative data collected by trained research assistants. Participants will receive $\mathrm{CDN} \$ 30$ for participating in interviews.

\section{Quantitative data}

Quantitative data will be collected via the following: (1) Administrative records of patients, care providers and PCCs that did and did not participate (reach and adoption); care providers trained, healthy food prescriptions prescribed, and healthy food incentives offered, earned and redeemed, including redemption location (implementation); (2) Implementation fidelity checklists (implementation) and (3) Quantitative questionnaire items completed by PCC staff and patients to report perceived programme outcomes (effectiveness); perceived programme experiences, facilitators, barriers, mechanisms of impact, quality of infrastructural supports and determinants of effective implementation (implementation); and longer-term programme feasibility, acceptability and willingness to participate in or deliver it, success in integrating the programme within existing workflows and how aspects of the programme were sustained over time (maintenance).

\section{Qualitative data}

Qualitative data will be collected via the following: (1) Reported reasons why patients, care providers and PCCs decline to participate in or drop out from the study (adoption and maintenance); (2) Qualitative questionnaire items completed by PCC staff and patients to provide suggestions for programme improvement (maintenance); (3) Notes from patient emails/calls to the study help-line (all domains); (4) Notes from meetings with PCC and supermarket staff liaisons (all domains); (5) Semistructured interviews with patients and members of the Indigenous advisory board (all domains) and (6) Qualitative observations of Indigenous advisory board meetings (all domains).

\section{Implementation fidelity}

From the measures summarised above, objective measures of implementation fidelity will include administrative records of healthy food prescriptions prescribed, and of healthy food incentives offered, earned and redeemed. Perceived measures of implementation fidelity will be reported by patients via quantitative checklists and semistructured interviews.

\section{Data analysis}

Quantitative data

Quantitative findings pertaining to all five RE-AIM domains will be summarised using descriptive statistics and will inform areas for subsequent in-depth qualitative exploration. We will stratify our analyses by clinic type (urban, rural, Indigenous) to examine any meaningful differences between them.

\section{Qualitative data}

Qualitative data will be coded by two trained researchers using directed content analysis, ${ }^{155}$ whereby development of an initial coding scheme for each set of interviews will be informed by RE-AIM, CFIR and other frameworks as appropriate. Concurrent data collection and analysis and regular meetings between researchers will permit iterative adjustments to the interview questions and coding schemes, and continuous evaluation of the adequacy of the samples. ${ }^{156}$ Sampling will end when new concepts are no longer being identified in the data.

\section{Data integration}

Quantitative and qualitative data will be integrated during the analysis stage for the purposes of expansion (eg, qualitative data will help to elaborate and explain quantitative findings) and convergence (eg, to examine whether quantitative and qualitative fidelity ratings correspond). ${ }^{157}$

\section{Data integration and dissemination}

Data from each of the three studies will be published separately, with an additional final publication that will integrate and synthesise their collective findings across all RE-AIM domains (table 4). These fully integrated data will be disseminated via technical reports, lay summaries, infographics, policy briefs, academic publications and oral/poster presentations.

\section{DISCUSSION}

Adults who are experiencing food insecurity cannot consume the healthy foods they require to manage their diabetes if they lack sufficient funds to purchase them. However, primary care providers often lack access to resources that could assist them to alleviate their patients' experiences of food insecurity. By addressing incomerelated causes of unhealthy dietary patterns and persistent hyperglycaemia, healthy food prescription programmes can equip clinicians with resources that assist their patients to maintain a healthier dietary pattern. Over the longer-term, maintenance of a healthier dietary pattern can improve health and reduce diabetes-related healthcare expenditures. $^{7-1564}$

We will investigate the RE-AIM of a healthy food prescription incentive programme for adults who are experiencing food insecurity and persistent hyperglycaemia. Through an RCT, modelling and implementation studies, 
Table 4 Integration of findings from the randomised controlled trial, implementation study and modelling study to describe the reach, effectiveness, adoption, implementation and maintenance of a healthy food prescription incentive programme

\begin{tabular}{llll}
\hline Reach & Effectiveness & Mdoption & Maintenance
\end{tabular}

\section{Randomised controlled trial \\ Impact on primary and \\ secondary outcomes}

\section{Implementation study}

Patient

representativeness participation and

\section{Perceived programme}

outcomes

\section{PCC and \\ care provider participation and representativeness}

Reasons why PCCs and care providers decline to participate
Perceived programme experiences, barriers, facilitators, providers and PCCs drop-out determinants of effective implementation, quality of infrastructural supports, mechanisms of impact

Care providers trained

intervention to other household members

Reasons why patients decline to participate
Healthy food prescriptions prescribed

Healthy food incentives offered, earned and redeemed

Implementation fidelity

Qualitative data from meetings, observations, semi-structured interviews, emails/calls to the help-line

$\begin{array}{ll}\text { Modelling study } & \\ & \text { Impact on longer-term } \\ & \text { health outcomes, } \\ & \text { resource use and costs }\end{array}$

PCC, primary care clinic.

we will generate comprehensive, in-depth and robust data pertaining to the short- and longer-term impacts of the programme on glycaemia, other health-related outcomes, resource use and costs, while also providing valuable implementation data to support translation of research findings into practice and policy. Integration of findings from these three studies acknowledges the reality that although evidence of short-term effectiveness from RCTs is valuable, such data are on their own insufficient to promote widespread and high quality implementation. In this respect, the implementation study will be critical to unpack determinants of effective implementation and reasons underlying the programme's successes and failures. Notably, our findings will be immediately relevant to existing programmes such as Wholesome Wave, which has been providing fruit and vegetable prescriptions to US households since $2010,{ }^{89}$ and can inform more specific recommendations regarding strategies to address food insecurity in patients with diabetes. ${ }^{10158}$ Moreover, opening up conversations around food insecurity may also provide a gateway to address other social determinants of health that constrain patients' health potential.
Potential risks and limitations

Our literature review ${ }^{43} 61$ 73-75 98 159-165 and stakeholder engagement identified several potential study risks. First, a single implementation model may not be effective for all PCCs, which could adversely affect implementation fidelity. We will, therefore, use a modified conjoint analysis to select PCC-specific implementation strategies, cocustomise and pilot test care pathways with PCCs to ensure compatibility, and monitor implementation fidelity. We will also provide comprehensive training with booster sessions, continuous technical support, and will meet weekly with staff designates and promptly address any concerns. Ongoing engagement, the support of operational leaders within the healthcare system and over-recruitment of PCCs will help to mitigate against and accommodate drop-out, should it occur. Primary risks at the patient level include failure to earn incentives or drop-out. To mitigate against these risks, participants will receive training regarding how to earn and redeem loyalty card points, weekly reminders to do so, and will have access to a study help-line for support. Whereas subsidies such as the Supplemental Nutrition 
Assistance Programme in the USA have been associated with stigma, ${ }^{166}$ we expect that the incentive format of the current programme may reduce stigmatising experiences, thereby increasing participant engagement with the programme. Moreover, both groups will receive CDN $\$ 100$ at baseline and follow-up as compensation, which will also serve as a recruitment incentive.

Participants' antihyperglycaemic regimen may be intensified by their care provider during the observation period, which can exert a significant impact on A1C. The tendency to intensification and deintensification should be balanced between groups owing to randomisation, nevertheless, we will monitor medication/insulin type/ dosage for use as adjustment variables in sensitivity analyses. In addition, need for antihyperglycaemic medication/insulin has been included as a secondary outcome, whereby deintensification will be considered a positive, and intensification a negative outcome.

Healthy food prescription programmes hold tremendous potential to improve health and reduce healthcare costs given that $20 \%$ of global morbidity and mortality is attributable to poor diet quality, ${ }^{167}$ and that food insecurity is a strong predictor of high-cost healthcare use. ${ }^{26} 168$ In addition, the benefits of such programmes extend to all household members, including children, for whom positive health outcomes may accrue across the lifecourse. In an era of unsustainable increases in healthcare costs, the healthcare system ignores the socioeconomic needs of patients at its peril. ${ }^{163}$ Failure to effectively address food insecurity among adults with T2DM portends unsustainable escalations in healthcare usage and costs. ${ }^{29} 32$ 36-38 168-170 We have proposed a comprehensive investigation of the RE-AIM of a healthy food prescription incentive programme. Ultimately, study findings will show whether a small upstream investment in a healthy food prescription incentive programme may avert substantially higher healthcare costs to treat diabetes complications after they emerge.

\section{Author affiliations}

${ }^{1}$ Department of Community Health Sciences, Cumming School of Medicine, University of Calgary, Calgary, Alberta, Canada

${ }^{2} 2$ Department of Medicine, Women's College Hospital, University of Toronto, Toronto, Ontario, Canada

${ }^{3}$ Indigenous Wellness Core, Alberta Health Services, Calgary, Alberta, Canada ${ }^{4}$ Department of Agricultural, Food \& Nutritional Sciences, University of Alberta, Edmonton, Alberta, Canada

${ }^{5}$ Knowledge Translation Platform, Alberta SPOR SUPPORT Unit, Department of Pediatrics, Faculty of Medicine \& Dentistry, University of Alberta, Edmonton, Alberta, Canada

${ }^{6}$ Department of Family Medicine, G012 Health Sciences Centre, 3330 Hospital Drive NW, Calgary, Alberta, Canada

${ }^{7}$ Department of Physiology, University of Alberta, Edmonton, Alberta, Canada

${ }^{8}$ Diabetes, Obesity and Nutrition Strategic Clinical Network, Alberta Health Services, Calgary, Alberta, Canada

${ }^{9}$ Nutrition Services, Alberta Health Services, Edmonton, Alberta, Canada

${ }^{10}$ Division of General Medicine and Clinical Epidemiology, Department of Medicine, University of North Carolina at Chapel Hill School of Medicine, Gatineau, Quebec, Canada

${ }^{11}$ Department of Medicine, Cumming School of Medicine, University of Calgary

Foothills Medical Centre, Calgary, Alberta, Canada
${ }^{12}$ Alberta Region, First Nations and Inuit Health Branch, Indigenous Services Canada, Edmonton, Alberta, Canada

${ }^{13}$ Department of Nutritional Sciences, Faculty of Medicine, University of Toronto,

Toronto, Ontario, Canada

${ }^{14}$ School of Public Health, University of Alberta, 3-300 Edmonton Clinic Health Academy, Edmonton, Alberta, Canada

${ }^{15}$ Faculty of Nursing, University of Alberta, Edmonton, Alberta, Canada

${ }^{16}$ Cardiovascular Health and Stroke Strategic Clinic Network, Alberta Health

Services, Calgary, Alberta, Canada

${ }^{17}$ Primary Health Care Integration Network, Primary Health Care, Alberta Health Services, Calgary, Alberta, Canada

${ }^{18}$ Department of Medicine, Faculty of Medicine and Dentistry, University of Alberta, Calgary, Alberta, Canada

${ }^{19}$ Department of Cardiac Sciences, Cumming School of Medicine, University Drive NW, Calgary, Alberta, Canada

Acknowledgements The authors would like to acknowledge the Registered Dietitians who developed the healthy food prescription pamphlet: Laura White, Suzanne Galesloot, Stephanie Krug, Kaylee Chichak, Erin Montgomery-Fajic, Monika Glassford and Kelly Berg.

Contributors DLO, RB, ES and DJTC conceived of the research, obtained funding and are leading its execution. DLO and DJTC drafted the manuscript. DLO, RB, ES, SD, LLL, KW, RO, SS, GLZ, KAM, KJDS, CBC, ST, SB, ALE, TS-S, ST, NP, LW, TW, ML'A, $\mathrm{KDR}, \mathrm{SN}, \mathrm{AN}, \mathrm{CB}-\mathrm{H}, \mathrm{CN}, \mathrm{PO}$ 'C, JS, RL, JC and DJTC contributed to study design, edited, read and approved the final manuscript.

Funding This work was supported by a Partnership for Research and Innovation in the Health System 5 grant from Alberta Innovates and Alberta Health Services (G2020000178), two Canadian Institutes of Health Research Patient-Oriented Research Early Career Investigator Awards (PJM-177970; PJM-175407) and a Canadian Institutes of Health Research Project Grant (PJI-474114). Food incentives are funded by Alberta Blue Cross, a not-for-profit supplemental health insurance provider. Nu Skin has provided in-kind support through the provision of skin carotenoid scanners.

Disclaimer The study funders had no role in study design, in writing the report or in the decision to submit it for publication.

Competing interests DLO and DJTC have received funding from a Petro-Canada Young Innovator Award in Community Health. The remaining authors declare that they have no competing interests.

Patient consent for publication Not applicable.

Provenance and peer review Not commissioned; externally peer reviewed.

Supplemental material This content has been supplied by the author(s). It has not been vetted by BMJ Publishing Group Limited (BMJ) and may not have been peer-reviewed. Any opinions or recommendations discussed are solely those of the author(s) and are not endorsed by BMJ. BMJ disclaims all liability and responsibility arising from any reliance placed on the content. Where the content includes any translated material, BMJ does not warrant the accuracy and reliability of the translations (including but not limited to local regulations, clinical guidelines, terminology, drug names and drug dosages), and is not responsible for any error and/or omissions arising from translation and adaptation or otherwise.

Open access This is an open access article distributed in accordance with the Creative Commons Attribution Non Commercial (CC BY-NC 4.0) license, which permits others to distribute, remix, adapt, build upon this work non-commercially, and license their derivative works on different terms, provided the original work is properly cited, appropriate credit is given, any changes made indicated, and the use is non-commercial. See: http://creativecommons.org/licenses/by-nc/4.0/.

\section{ORCID iDs}

Dana Lee Olstad http://orcid.org/0000-0001-9787-9952

Seth Berkowitz http://orcid.org/0000-0003-1030-4297

David J T Campbell http://orcid.org/0000-0002-5570-3630

\section{REFERENCES}

1 American Diabetes Association. Economic costs of diabetes in the U.S. in 2017. Diabetes Care 2018;41:917-28.

2 Health care system cost of people with diabetes, 2013. Available: https://open.alberta.ca/dataset/a2a60d91-081e-42c8- 
8d4a-466bb3506399/resource/34c90d83-caa3-4def-ab783a8987e2d7d7/download/phsb-03-2013-diabetes-cost.pdf

3 New diabetes rates released with urgent plea for governments to implement national diabetes strategy, 2019. Available: https:// www.diabetes.ca/media-room/press-releases/new-diabetesrates-released-with-urgent-plea-for-governments-to-implementnational-diabetes-strategy\#: :text=Jan\%20Hux\%2C\%20 President\%20and\%20CEO,under\%20\%2430\%20billion\% 20this\%20year

4 Quantitative Economic Decisions Inc: Canadian Diabetes Cost Model. The Canadian Diabetes Cost Model was developed for diabetes Canada by quantitative economic decisions, Inc. (formerly Informetrica Limited) and publicly released in 2009. The forecasting model provides projections about the prevalence, incidence and economic burden of diabetes for Canadian society based on national surveillance data from the Canadian chronic disease surveillance system 2009.

5 O'Reilly DJ, Xie F, Pullenayegum E, et al. Estimation of the impact of diabetes-related complications on health utilities for patients with type 2 diabetes in Ontario, Canada. Qual Life Res 2011;20:939-43.

6 Bradley C, Speight J. Patient perceptions of diabetes and diabetes therapy: assessing quality of life. Diabetes Metab Res Rev 2002;18:S64-9.

7 Sievenpiper JL, Chan CB, Dworatzek PD, et al. Nutrition therapy. Canadian J Diabetes 2018;42:S64-79.

8 Evert AB, Dennison M, Gardner CD, et al. Nutrition therapy for adults with diabetes or prediabetes: a consensus report. Diabetes Care 2019;42:731-54.

9 Neuenschwander M, Ballon A, Weber KS, et al. Role of diet in type 2 diabetes incidence: umbrella review of meta-analyses of prospective observational studies. BMJ 2019;366:12368.

10 American Diabetes Association. Improving care and promoting health in populations: standards of medical care in diabetes-2019. Diabetes Care 2019;42:S7-12.

11 Stratton IM, Adler AI, Neil HA, et al. Association of glycaemia with macrovascular and microvascular complications of type 2 diabetes (UKPDS 35): prospective observational study. BMJ 2000;321:405-12.

12 UK Prospective Diabetes Study (UKPDS) Group. Effect of intensive blood-glucose control with metformin on complications in overweight patients with type 2 diabetes (UKPDS 34). UK prospective diabetes study (UKPDS) group. Lancet 1998;352:854-65

13 UK Prospective Diabetes Study (UKPDS) Group. Intensive blood-glucose control with sulphonylureas or insulin compared with conventional treatment and risk of complications in patients with type 2 diabetes (UKPDS 33). UK prospective diabetes study (UKPDS) group. Lancet 1998;352:837-53

14 Zhu C-H, Zhang S-S, Kong Y, et al. Effects of intensive control of blood glucose and blood pressure on microvascular complications in patients with type II diabetes mellitus. Int $\mathrm{J}$ Ophthalmol 2013;6:141-5

15 Antonio JP, Sarmento RA, de Almeida JC. Diet quality and glycemic control in patients with type 2 diabetes. J Acad Nutr Diet 2019;119:652-8.

16 Nathan DM, Kuenen J, Borg R, et al. Translating the A1C assay into estimated average glucose values. Diabetes Care 2008;31:1473-8.

17 Little RR, Rohlfing CL, Sacks DB, et al. Status of hemoglobin A1c measurement and goals for improvement: from chaos to order for improving diabetes care. Clin Chem 2011;57:205-14

18 Rao M, Afshin A, Singh G, et al. Do healthier foods and diet patterns cost more than less healthy options? A systematic review and meta-analysis. BMJ Open 2013;3:e004277.

19 Canada's Food Price Report 10th edition 2020, 2020. Available: https://cdn.dal.ca/content/dam/dalhousie/pdf/sites/agri-food/ Canada\%20Food\%20Price\%20Report\%20Eng\%202020.pdf

20 Campbell DJT, Ronksley PE, Hemmelgarn BR, et al. Association of enrolment in primary care networks with diabetes care and outcomes among first nations and low-income Albertans. Open Med 2012;6:e155-65.

21 McBrien KA, Manns BJ, Hemmelgarn BR, et al. The association between sociodemographic and clinical characteristics and poor glycaemic control: a longitudinal cohort study. Diabet Med 2016;33:1499-507.

22 Deved V, Jette N, Quan H, et al. Quality of care for first nations and non-First nations people with diabetes. Clin J Am Soc Nephrol 2013;8:1188-94.

23 Dyck RF, Sidhu N, Klomp H, et al. Differences in glycemic control and survival predict higher ESRD rates in diabetic first nations adults. Clin Invest Med 2010;33:E390-7.
24 McBrien KA, Manns BJ, Chui B, et al. Health care costs in people with diabetes and their association with glycemic control and kidney function. Diabetes Care 2013;36:1172-80.

25 Household food insecurity by Province and Territory, 2014, 2014. Available: https://proof.utoronto.ca/food-insecurity/

26 Fitzpatrick T, Rosella LC, Calzavara A, et al. Looking beyond income and education: socioeconomic status gradients among future highcost users of health care. Am J Prev Med 2015;49:161-71.

27 Mayer VL, McDonough K, Seligman H, et al. Food insecurity, coping strategies and glucose control in low-income patients with diabetes. Public Health Nutr 2016;19:1103-11.

28 Berkowitz SA, Baggett TP, Wexler DJ, et al. Food insecurity and metabolic control among U.S. adults with diabetes. Diabetes Care 2013;36:3093-9.

29 Seligman HK, Davis TC, Schillinger D, et al. Food insecurity is associated with hypoglycemia and poor diabetes self-management in a low-income sample with diabetes. J Health Care Poor Underserved 2010;21:1227-33.

30 Seligman HK, Jacobs EA, Lopez A, et al. Food insecurity and hypoglycemia among safety net patients with diabetes. Arch Intern Med 2011;171:1204-6.

31 Berkowitz SA, Gao X, Tucker KL. Food-insecure dietary patterns are associated with poor longitudinal glycemic control in diabetes: results from the Boston Puerto Rican health study. Diabetes Care 2014;37:2587-92.

32 Berkowitz SA, Meigs JB, DeWalt D, et al. Material need insecurities, control of diabetes mellitus, and use of health care resources: results of the measuring economic insecurity in diabetes study. JAMA Intern Med 2015;175:257-65.

33 Silverman J, Krieger J, Kiefer M, et al. The relationship between food insecurity and depression, diabetes distress and medication adherence among low-income patients with poorly-controlled diabetes. J Gen Intern Med 2015;30:1476-80.

34 Heerman WJ, Wallston KA, Osborn CY, et al. Food insecurity is associated with diabetes self-care behaviours and glycaemic control. Diabet Med 2016;33:844-50.

35 Gucciardi E, Vahabi M, Norris N, et al. The intersection between food insecurity and diabetes: a review. Curr Nutr Rep 2014;3:324-32.

36 Nelson K, Cunningham W, Andersen R, et al. Is food insufficiency associated with health status and health care utilization among adults with diabetes? J Gen Intern Med 2001;16:404-11.

37 Seligman HK, Bolger AF, Guzman D, et al. Exhaustion of food budgets at month's end and hospital admissions for hypoglycemia. Health Aff 2014;33:116-23.

38 Gucciardi E, Vogt JA, DeMelo M, et al. Exploration of the relationship between household food insecurity and diabetes in Canada. Diabetes Care 2009;32:2218-24.

39 Diabetes Canada Clinical Practice Guidelines Expert Committee, Imran SA, Agarwal G, et al. Targets for glycemic control. Can J Diabetes 2018;42:S42-6.

40 Diabetes incidence among first nations in Alberta, 2017. Available: http://www.afnigc.ca/main/includes/media/pdf/fnhta/HTAFN-201704-04-Diabetes Incidence.pdf

41 The first nations regional health survey. Phase 3: Volume 2, 2018. Available: https://fnigc.ca/sites/default/files/docs/fnigc_rhs_phase_ 3 volume two en final screen.pdf

42 Household food insecurity in Canada, 2017-2018, 2020. Available: https://proof.utoronto.ca/food-insecurity/

43 Aiyer JN, Raber M, Bello RS, et al. A pilot food prescription program promotes produce intake and decreases food insecurity. Transl Behav Med 2019;9:922-30.

44 Forbes JM, Forbes CR, Lehman E, et al. "Prevention produce": integrating medical student mentorship into a fruit and vegetable prescription program for at-risk patients. Perm J 2019;23.

45 Wetherill MS, Chancellor Mclntosh H, Beachy C, et al. Design and implementation of a clinic-based food pharmacy for food insecure, uninsured patients to support chronic disease self-management. J Nutr Educ Behav 2018;50:947-9.

46 Impacts of the fruit and vegetable prescription program, 2015 Available: https://www.wholesomewave.org/sites/default/files/wpcontent/uploads/2016/02/BCBS_FVRxReport.pdf

47 Ridberg RA, Bell JF, Merritt KE, et al. A pediatric fruit and vegetable prescription program increases food security in low-income households. J Nutr Educ Behav 2019;51:e221:224-30.

48 Trapl ES, Smith S, Joshi K, et al. Dietary impact of produce prescriptions for patients with hypertension. Prev Chronic Dis 2018:15:E138.

49 Cavanagh M, Jurkowski J, Bozlak C, et al. Veggie Rx: an outcome evaluation of a healthy food incentive programme. Public Health Nutr 2017;20:2636-41. 
50 Wholesome Wave's fruit and vegetable prescription program, New York City 2013 outcomes, 2013. Available: https://www. wholesomewave.org/sites/default/files/wp-content/uploads/2014/ 10/FVRx-2013 HHC Report.pdf

51 Wholesome Wave's fruit and vegetable prescription program, New York City 2014 outcomes, 2014. Available: https://www. wholesomewave.org/sites/default/files/wp-content/uploads/2014/ 10/FVRx-2013_HHC_Report.pdf

52 Wholesome wave's fruit and vegetable prescription program 2013 report, 2014. Available: https://www.wholesomewave.org/sites/ default/files/wp-content/uploads/2014/10/2013-FVRxReport_-Final1.pdf

53 Wholesome wave's fruit and vegetable prescription program 2012 program report, 2012. Available: https://www.wholesomewave.org/ sites/default/files/wp-content/uploads/2014/07/FVRx_2012Report FINAL.pdf

54 Black AP, Vally $\mathrm{H}$, Morris $\mathrm{P}$, et al. Nutritional impacts of a fruit and vegetable subsidy programme for disadvantaged Australian Aboriginal children. Br J Nutr 2013;110:2309-17.

55 Black AP, Vally H, Morris PS, et al. Health outcomes of a subsidised fruit and vegetable program for Aboriginal children in northern New South Wales. Med J Aust 2013;199:46-50.

56 Bryce R, Guajardo C, llarraza D, et al. Participation in a farmers market fruit and vegetable prescription program at a federally qualified health center improves hemoglobin A1C in low income uncontrolled diabetics. Prev Med Rep 2017;7:176-9.

57 Jones LJ, VanWassenhove-Paetzold J, Thomas K, et al. Impact of a fruit and vegetable prescription program on health outcomes and behaviors in young Navajo children. Curr Dev Nutr 2020;4:nzaa109.

58 Veldheer S, Scartozzi C, Bordner CR, et al. Impact of a prescription produce program on diabetes and cardiovascular risk outcomes. J Nutr Educ Behav 2021;53:1008-17.

59 Kerr D, Barua S, Glantz N, et al. Farming for life: impact of medical prescriptions for fresh vegetables on cardiometabolic health for adults with or at risk of type 2 diabetes in a predominantly Mexican-American population. BMJ Nutr Prev Health 2020;3:239-46.

60 Bhat S, Coyle DH, Trieu K, et al. Healthy food prescription programs and their impact on dietary behavior and cardiometabolic risk factors: a systematic review and meta-analysis. Adv Nutr 2021;12:1944-56.

61 Friedman DB, Freedman DA, Choi SK, et al. Provider communication and role modeling related to patients' perceptions and use of a federally qualified health Center-Based farmers' market. Health Promot Pract 2014;15:288-97.

62 Trapl ES, Joshi K, Taggart M, et al. Mixed methods evaluation of a produce prescription program for pregnant women. J Hunger Environ Nutr 2017;12:529-43.

63 Buyuktuncer Z, Kearney M, Ryan CL, et al. Fruit and vegetables on prescription: a brief intervention in primary care. J Hum Nutr Diet 2014;27:186-93.

64 Lee Y, Mozaffarian D, Sy S, et al. Cost-effectiveness of financial incentives for improving diet and health through Medicare and Medicaid: a microsimulation study. PLoS Med 2019;16:e1002761.

65 Freedman DA, Choi SK, Hurley T, et al. A farmers' market at a federally qualified health center improves fruit and vegetable intake among low-income diabetics. Prev Med 2013;56:288-92.

66 Zhou X, Siegel KR, Ng BP, et al. Cost-effectiveness of diabetes prevention interventions targeting high-risk individuals and whole populations: a systematic review. Diabetes Care 2020;43:1593-616.

67 Curran GM, Bauer M, Mittman B, et al. Effectivenessimplementation hybrid designs: combining elements of clinical effectiveness and implementation research to enhance public health impact. Med Care 2012;50:217-26.

68 Glasgow RE, Nelson CC, Strycker LA, et al. Using RE-AIM metrics to evaluate diabetes self-management support interventions. Am J Prev Med 2006;30:67-73.

69 Glasgow RE, Vogt TM, Boles SM. Evaluating the public health impact of health promotion interventions: the RE-AIM framework. Am J Public Health 1999;89:1322-7.

70 The First Nations Principles of OCAP, 2019. Available: https://www. afn.ca/uploads/files/nihbforum/info_and_privacy_doc-ocap.pdf

71 Tri-Council policy statement: ethical conduct for research involving humans - TCPS 2 (2018), 2018. Available: http://www.pre.ethics.gc ca/eng/policy-politique tcps2-eptc2 2018.html

72 Indigenous health transformational roadmap 2018-2020, 2018. Available: https://www.albertahealthservices.ca/assets/about/scn/ ahs-scn-ppih-ih-roadmap.pdf

73 Campbell DJT, Manns BJ, Hemmelgarn BR, et al. Understanding financial barriers to care in patients with diabetes. Diabetes Educ 2017;43:78-86.
74 Campbell DJT, Manns BJ, Leblanc P, et al. Finding resiliency in the face of financial barriers: development of a conceptual framework for people with cardiovascular-related chronic disease. Medicine 2016:95:e5561.

75 Kulhawy-Wibe S, King-Shier KM, Barnabe C, et al. Exploring structural barriers to diabetes self-management in Alberta first nations communities. Diabetol Metab Syndr 2018;10:87.

76 Campbell D, Campbell R, Larsen M. Home Sweet Home(less): Giving diabetes a voice from the street - Images and stories from a community-based photovoice project. In: North American Primary Care Research Group Annual Meeting. Toronto, ON 2019.

77 Campbell D, Campbell R, Larsen M. Creating together: designing and conducting a community-based participatory research project. In: Canadian alliance to end homelessness annual meeting, Edmonton, AB 2019.

78 Indigenous food sovereignty. Available: https://foodsecurecanada org/resources-news/newsletters/1-indigenous-food-sovereignty

79 Barnard LS, Wexler DJ, DeWalt D, et al. Material need support interventions for diabetes prevention and control: a systematic review. Curr Diab Rep 2015;15:574.

80 Hager ER, Quigg AM, Black MM, et al. Development and validity of a 2-item screen to identify families at risk for food insecurity. Pediatrics 2010;126:e26-32.

81 Gundersen C, Engelhard EE, Crumbaugh AS, et al. Brief assessment of food insecurity accurately identifies high-risk US adults. Public Health Nutr 2017;20:1367-71.

82 Makelarski JA, Abramsohn E, Benjamin JH, et al. Diagnostic accuracy of two food insecurity screeners recommended for use in health care settings. Am J Public Health 2017;107:1812-7.

83 Hagenaars A, de Vos K. The definition and measurement of poverty. J Hum Resour 1988;23:211-21.

84 Litwin H, Sapir EV. Perceived income adequacy among older adults in 12 countries: findings from the survey of health, ageing, and retirement in Europe. Gerontologist 2009;49:397-406.

85 Gildner TE, Liebert MA, Capistrant BD, et al. Perceived income adequacy and well-being among older adults in six low- and middle-income countries. J Gerontol B Psychol Sci Soc Sci 2019;74:516-25.

86 Al Hamarneh YN, Charrois T, Lewanczuk R, et al. Pharmacist intervention for glycaemic control in the community (the RxING study). BMJ Open 2013;3:e003154.

87 Olsho LE, Klerman JA, Wilde PE, et al. Financial incentives increase fruit and vegetable intake among supplemental nutrition assistance program participants: a randomized controlled trial of the USDA healthy incentives pilot. Am J Clin Nutr 2016;104:423-35.

88 Browne AJ, Varcoe C, Ford-Gilboe M, et al. EQUIP healthcare: an overview of a multi-component intervention to enhance equityoriented care in primary health care settings. Int J Equity Health 2015;14:152.

89 Frut and vegetable prescription program, 2019. Available: https:// www.wholesomewave.org/

90 Mayne SL, Auchincloss AH, Michael YL. Impact of policy and built environment changes on obesity-related outcomes: a systematic review of naturally occurring experiments. Obes Rev 2015;16:362-75.

91 McGill R, Anwar E, Orton L, et al. Are interventions to promote healthy eating equally effective for all? Systematic review of socioeconomic inequalities in impact. BMC Public Health 2015;15:457.

92 Ni Mhurchu C, Blakely T, Jiang Y, et al. Effects of price discounts and tailored nutrition education on supermarket purchases: a randomized controlled trial. Am J Clin Nutr 2010;91:736-47.

93 Burr ML, Ashfield-Watt PAL, Dunstan FDJ, et al. Lack of benefit of dietary advice to men with angina: results of a controlled trial. Eur $J$ Clin Nutr 2003;57:193-200.

94 Burr ML, Trembeth J, Jones KB, et al. The effects of dietary advice and vouchers on the intake of fruit and fruit juice by pregnant women in a deprived area: a controlled trial. Public Health Nutr 2007;10:559-65.

95 Ness AR, Hughes J, Elwood PC, et al. The long-term effect of dietary advice in men with coronary disease: follow-up of the diet and reinfarction trial (dart). Eur J Clin Nutr 2002;56:512-8.

96 Fafard St-Germain A-A, Tarasuk V. Prioritization of the essentials in the spending patterns of Canadian households experiencing food insecurity. Public Health Nutr 2018;21:2065-78.

97 Khan MI, Weinstock RS. Carbohydrates. In: McPherson RA, Pincus MR, eds. Henry's clinical diagnosis and management by laboratory methods. 22nd edn. Philadephia, PA: Saunders Elsevier, 2011: 210-25. 
98 Goddu AP, Roberson TS, Raffel KE, et al. Food Rx: a communityuniversity partnership to prescribe healthy eating on the South side of Chicago. J Prev Interv Community 2015;43:148-62.

99 Nutrition guideline diabetes, 2016. Available: https://www.albertah ealthservices.ca/assets/info/nutrition/if-nfs-ng-diabetes.pdf

100 Canadian Community Health Survey - annual component (CCHS), 2020. Available: https://www23.statcan.gc.ca/imdb/p3lnstr.pl? Function=assemblelnstr\&lang=en\&ltem_Id $=1262397$

101 Milton K, Bull FC, Bauman A. Reliability and validity testing of a single-item physical activity measure. Br J Sports Med 2011;45:203-8.

102 Topp CW, Østergaard SD, Søndergaard S, et al. The WHO-5 well-being index: a systematic review of the literature. Psychother Psychosom 2015;84:167-76.

103 Lorig K, Stewart A, Ritter P. Outcome measures for health education and other health care interventions. Vol. 2019. Thousand Oaks, CA: Sage, 1996.

104 Self-efficacy for diabetes, 2009. Available: https://www.selfmana gementresource.com/docs/pdfs/English_-_self-efficacy_diabetes. pdf

105 Schmitt A, Reimer A, Hermanns N, et al. Assessing diabetes selfmanagement with the diabetes self-management questionnaire (DSMQ) can help analyse behavioural problems related to reduced glycaemic control. PLoS One 2016;11:e0150774.

106 Schmitt A, Gahr A, Hermanns N, et al. The diabetes selfmanagement questionnaire (DSMQ): development and evaluation of an instrument to assess diabetes self-care activities associated with glycaemic control. Health Qual Life Outcomes 2013;11:138.

107 McGuire BE, Morrison TG, Hermanns N, et al. Short-form measures of diabetes-related emotional distress: the Problem Areas in Diabetes Scale (PAID)-5 and PAID-1. Diabetologia 2010;53:66-9.

108 EQ-5D-5L, 2020. Available: https://euroqol.org/eq-5d-instruments/ eq-5d-5I-about/

109 Work productivity and activity impairment questionnaire, 2004. Available: http://www.reillyassociates.net/WPAl_GH.htm

110 Household food insecurity in Canada: a guide to measurement and interpretation, 2018. Available: https://proof.utoronto.ca/wpcontent/uploads/2018/11/Household-Food-Insecurity-in-Canada-AGuide-to-Measurement-and-Interpretation.pdf

111 Determining food security status, 2012. Available: https://www. canada.ca/en/health-canada/services/food-nutrition/food-nutritionsurveillance/health-nutrition-surveys/canadian-communityhealth-survey-cchs/household-food-insecurity-canada-overview/ determining-food-security-status-food-nutrition-surveillance-healthcanada.html

112 The household food security survey module (HFSSM), 2012. Available: https://www.canada.ca/en/health-canada/services/ food-nutrition/food-nutrition-surveillance/health-nutrition-surveys/ canadian-community-health-survey-cchs/household-foodinsecurity-canada-overview/household-food-security-surveymodule-hfssm-health-nutrition-surveys-health-canada.html

113 Kalichman SC, Amaral CM, Swetzes C, et al. A simple singleitem rating scale to measure medication adherence: further evidence for convergent validity. J Int Assoc Physicians AIDS Care 2009;8:367-74.

114 Seligman HK, Lyles C, Marshall MB. A pilot food bank intervention featuring diabetes-appropriate food improved glycemic control among clients in three states. Health Aff 2015;34:1956-63.

115 Barriers to care for people with chronic health conditions (BCPCHC), 2011. Available: http://www23.statcan.gc.ca/imdb/ p2SV.pl?Function=getSurvey\&SDDS $=5189$

116 Macarthur subjective social status scale, 2019. Available: https:// macses.ucsf.edu/research/psychosocial/subjective.php

117 Cundiff JM, Smith TW, Uchino BN, et al. Subjective social status: construct validity and associations with psychosocial vulnerability and self-rated health. Int J Behav Med 2013;20:148-58.

118 Subar AF, Kirkpatrick SI, Mittl B, et al. The automated selfadministered 24-hour dietary recall (ASA24): a resource for researchers, clinicians, and educators from the National cancer Institute. J Acad Nutr Diet 2012;112:1134-7.

119 Kirkpatrick SI, Subar AF, Douglass D, et al. Performance of the automated self-administered 24-hour recall relative to a measure of true intakes and to an interviewer-administered 24-h recall. $A m \mathrm{~J}$ Clin Nutr 2014;100:233-40.

120 ASA24-Canada, 2020. Available: https://epi.grants.cancer.gov/ asa24/respondent/asa24-canada-2018.html

121 Park Y, Dodd KW, Kipnis V, et al. Comparison of self-reported dietary intakes from the automated self-administered $24-h$ recall, 4-d food records, and food-frequency questionnaires against recovery biomarkers. Am J Clin Nutr 2018;107:80-93.
122 Thompson FE, Subar AF. Dietary assessment methodology. In: Coulston AM, Boushey CJ, Ferruzzi MG, eds. Nutrition in the prevention and treatment of disease. 3rd edn. London: Elsevier, 2013: 5-46.

123 Krebs-Smith SM, Pannucci TE, Subar AF, et al. Update of the healthy eating index: HEl-2015. J Acad Nutr Diet 2018:118:1591-602.

124 Kirkpatrick SI, Reedy J, Krebs-Smith SM, et al. Applications of the healthy eating index for surveillance, epidemiology, and intervention research: considerations and caveats. J Acad Nutr Diet 2018;118:1603-21.

125 American Diabetes Association. Standards of medical care in diabetes-2007. Diabetes Care 2007;30:S4-41.

126 Sacks DB, Arnold M, Bakris GL, et al. Guidelines and recommendations for laboratory analysis in the diagnosis and management of diabetes mellitus. Clin Chem 2011;57:e1-47.

127 American Diabetes Association, European Association for the Study of Diabetes, International Federation of Clinical Chemistry and Laboratory Medicine, et al. Consensus statement on the worldwide standardisation of the $\mathrm{HbA} 1 \mathrm{c}$ measurement. Diabetologia 2007;50:2042-3.

128 Berard LD, Siemens R, Woo V. Monitoring glycemic control. Canadian Journal of Diabetes 2018:42:S47-53.

129 Baker JR, Johnson RN, Scott DJ. Serum fructosamine concentrations in patients with type II (non-insulin-dependent) diabetes mellitus during changes in management. $\mathrm{Br} M e d \mathrm{~J}$ 1984;288:1484-6.

130 Radtke MD, Pitts SJ, Jahns L, et al. Criterion-related validity of spectroscopy-based skin carotenoid measurements as a proxy for fruit and vegetable intake: a systematic review. Adv Nutr 2020;11:1282-99.

131 Alberta health data asset directory, 2018. Available: https:// albertarwe.ca/wp-content/uploads/2018/07/Alberta-Health-DataAsset-Directory-2018.pdf

132 Cheng XH, Jo Y, Kim J. Heterogeneous impact of supplemental nutrition assistance program benefit changes on food security by local prices. Am J Prev Med 2020;58:e97-103.

133 Brassard D, Elvidge Munene L-A, St Pierre S, et al. Development of the Healthy Eating Food Index (HEFI)-2019 measuring adherence to Canada's Food Guide 2019 recommendations on healthy food choices. Appl Physiol Nutr Metab 2022. doi:10.1139/apnm-20210415. [Epub ahead of print: 14 Jan 2022].

134 Diabetes Canada Clinical Practice Guidelines Expert Committee, Lipscombe L, Booth G, et al. Pharmacologic glycemic management of type 2 diabetes in adults. Can J Diabetes 2018;42:S88-103.

135 Dimitri C, Oberholtzer L, Zive M, et al. Enhancing food security of low-income consumers: an investigation of financial incentives for use at farmers markets. Food Policy 2015;52:64-70.

136 An analysis of sample attrition in panel data: the Michigan panel study of income dynamics, 1997. Available: http://www.nber.org/ papers/t0220.pdf

137 Testing and adjusting for attrition in household panel data, 2011. Available: http://www.chronicpoverty.org/publications/details/ testing-and-adjusting-for-attrition-in-household-panel-data

138 Li P, Stuart EA. Best (but oft-forgotten) practices: missing data methods in randomized controlled nutrition trials. Am J Clin Nutr 2019;109:504-8.

139 Scharfstein D, McDermott A, Díaz I, et al. Global sensitivity analysis for repeated measures studies with informative drop-out: a semiparametric approach. Biometrics 2018;74:207-19.

140 Alberta wage and salary survey, 2017. Available: https://www. alberta.ca/wage-salary-information.aspx\#toc-1

141 Hayes AJ, Leal J, Gray AM, et al. UKPDS outcomes model 2: a new version of a model to simulate lifetime health outcomes of patients with type 2 diabetes mellitus using data from the 30 year United Kingdom prospective diabetes study: UKPDS 82. Diabetologia 2013:56:1925-33

142 EQ-5D, 2019. Available: https://euroqol.org/

143 Damschroder LJ, Aron DC, Keith RE, et al. Fostering implementation of health services research findings into practice: a consolidated framework for advancing implementation science. Implement Sci 2009;4:50.

144 Meyers DC, Durlak JA, Wandersman A. The quality implementation framework: a synthesis of critical steps in the implementation process. Am J Community Psychol 2012;50:462-80.

145 Meyers DC, Katz J, Chien V, et al. Practical implementation science: developing and piloting the quality implementation tool. Am J Community Psychol 2012;50:481-96.

146 Indigenous peoples in Canada video and leaning series, 2019. Available: https://www.albertahealthservices.ca/info/page7634.aspx 
147 Equipping for equity online modules, 2019. Available: https:// equiphealthcare.ca/toolkit/

148 Lewis CC, Scott K, Marriott BR. A methodology for generating a tailored implementation blueprint: an exemplar from a youth residential setting. Implement Sci 2018;13:68.

149 CFIR stakeholder survey, 2019. Available: https://cfirguide.org/ evaluation-design/overview/

150 Powell BJ, Waltz TJ, Chinman MJ, et al. A refined compilation of implementation strategies: results from the expert recommendations for implementing change (ERIC) project. Implement Sci 2015;10:21.

151 Powell BJ, Beidas RS, Lewis CC, et al. Methods to improve the selection and tailoring of implementation strategies. J Behav Health Serv Res 2017;44:177-94.

152 Waltz TJ, Powell BJ, Fernández ME, et al. Choosing implementation strategies to address contextual barriers: diversity in recommendations and future directions. Implement Sci 2019;14:42.

153 Lavis JN, Boyko JA, Gauvin F-P. Evaluating deliberative dialogues focussed on healthy public policy. BMC Public Health 2014;14:1287.

154 Lavis JN, Boyko JA, Oxman AD, et al. Support tools for evidenceinformed health Policymaking (STP) 14: organising and using policy dialogues to support evidence-informed policymaking. Health Res Policy Syst 2009;7:S14.

155 Hsieh H-F, Shannon SE. Three approaches to qualitative content analysis. Qual Health Res 2005;15:1277-88.

156 Malterud K, Siersma VD, Guassora AD. Sample size in qualitative interview studies: guided by information power. Qual Health Res 2015.

157 Palinkas LA, Mendon SJ, Hamilton AB. Innovations in mixed methods evaluations. Annu Rev Public Health 2019;40:423-42.

158 Food security and diabetes: a position statement, 2020. Available: https://www.diabetes.ca/en-CA/advocacy-policies/our-policypositions/food-security-and-diabetes?utm_source=eBlast June2020\&utm_medium=eblast\&utm_campaign=newsletter\&utm_ content=hyperlink_txt

159 Morton S. Progressing research impact assessment: a 'contributions' approach. Res Eval 2015;24:405-19.

160 Moscrop A, Ziebland S, Roberts N, et al. A systematic review of reasons for and against asking patients about their socioeconomic contexts. Int J Equity Health 2019;18:112.

161 We ask because we care. The Tri-Hospital + TPH health equity data collection research project report, 2018. Available: http://www. stmichaelshospital.com/quality/equity-data-collection-report.pdf
162 Naz A, Rosenberg E, Andersson N, et al. Health workers who ask about social determinants of health are more likely to report helping patients: mixed-methods study. Can Fam Physician 2016;62:e684-93.

163 Health Care's Blind Side. The overlooked connection between social needs and good health, 2011. Available: https://www.rwjf. org/en/library/articles-and-news/2011/12/health-cares-blind-sideunmet-social-needs-leading-to-worse-heal.html

164 Anderson ES, Lippert S, Newberry J, et al. Addressing social determinants of health from the emergency department through social emergency medicine. West J Emerg Med 2016;17:487-9.

165 Schickedanz A, Hamity C, Rogers A, et al. Clinician experiences and attitudes regarding screening for social determinants of health in a large integrated health system. Med Care 2019;57:S197-201.

166 Pak T-Y, Kim G. Food stamps, food insecurity, and health outcomes among elderly Americans. Prev Med 2020;130:105871.

167 GBD 2017 Diet Collaborators. Health effects of dietary risks in 195 countries, 1990-2017: a systematic analysis for the global burden of disease study 2017. Lancet 2019;393:1958-72.

168 Tarasuk V, Cheng J, de Oliveira C, et al. Association between household food insecurity and annual health care costs. CMAJ 2015;187:E429-36.

169 Fitzpatrick C, Datta GD, Henderson M, et al. School food environments associated with adiposity in Canadian children. Int J Obes 2017;41:1005-10.

170 Campbell DJT, Manns BJ, Weaver RG, et al. Financial barriers and adverse clinical outcomes among patients with cardiovascularrelated chronic diseases: a cohort study. BMC Med 2017;15:33.

171 Canadian community health survey public use Microdata files, 2015-16. Available: https://www-statcan-gc-ca.ezproxy.lib.ucalgary. ca/eng/reference/licence

172 Tonelli M, Wiebe N, Richard J-F, et al. Characteristics of adults with type 2 diabetes mellitus by category of chronic kidney disease and presence of cardiovascular disease in Alberta Canada: a cross-sectional study. Can J Kidney Health Dis 2019;6:2054358119854113.

173 First nations food, nutrition \& environment study, 2019. Available: http://www.fnfnes.ca/

174 Galesloot S, Mclntyre L, Fenton T, et al. Food insecurity in Canadian adults receiving diabetes care. Can J Diet Pract Res 2012;73:e261-6.

175 Juarez D, Goo R, Tokumaru S, et al. Association between sustained glycated hemoglobin control and healthcare costs. Am J Pharm Benefits 2013;5:59-64. 